\title{
Analysis of Public Procurement Planning Practices on Provision of Quality Health Care Services at Nakuru Level V Hospital, Kenya
}

\author{
Francis Mathenge Kingo'ri, Josphat Kwasira \\ College of Human Resource Development, Jomo Kenyatta University of Agriculture and Technology, Nakuru, Kenya
}

\section{Email address:}

mathengekingori@gmail.com (F. M. Kingo'ri), jkwasira7@gmail.com (J. Kwasira)

\section{To cite this article:}

Francis Mathenge Kingo'ri, Josphat Kwasira. Analysis of Public Procurement Planning Practices on Provision of Quality Health Care Services at Rift Valley Provincial and General Hospital, Kenya. Journal of Investment and Management. Vol. 5, No. 5, 2016, pp. 51-63. doi: $10.11648 /$ j.jim.20160505.13

Received: August 21, 2016; Accepted: September 13, 2016; Published: September 23, 2016

\begin{abstract}
Over the recent past, quality of health care has been a major concern for various stakeholders in Kenya. A number of programs such as Beyond Zero campaign, investment in Kidney Dialysis machines, Cancer Scanning machines among others have been launched towards quality health care. It is in this light that this study delves into the influence of public procurement planning practices on provision of quality health care services. Procurement planning involves material requirement planning, resource planning and capacity planning which will be linked to health care service quality. The indicators of procurement planning are used to formulate the specific objectives. The theories on which the study was based on include the Resource Based View Theory and Systems Theory. The research used survey design as only one organization was studied. Therefore, the target population was comprised of top, middle and lower level managers which totals to 98 at Nakuru General Hospital. The study adopted stratified random sampling which gave a sample of 79 managers to be included in the study. Questionnaire was used to collect necessary data and the questionnaire was closed ended. The data collected was then processed using SPSS. Inferential statistics was conducted to test the relationship between the variable where Karl Pearson correlation coefficient was used. Further, descriptive statistics was used where mean and standard deviation were used for generalization of respondent's opinions. The findings of the study are beneficial towards enhancing health care quality at the Nakuru Level V Hospital. Further, it is beneficial to other Hospitals around the Country struggling with offering quality health care services with respect to the role of procurement planning in achieving the same. The results $(\mathrm{p}=0.001)$ indicated that there is a statistically significant relationship between public procurement planning practices and provision of quality health care because $\mathrm{P}$ value is less than 0.05 . Regarding the influence of public procurement planning and quality health care, the study established that capacity planning had the greatest influence on quality health care $($ Beta $=.372)$, followed by master production schedule $($ Beta $=.359)$, then resource planning $($ Beta $=.117)$ and finally material requirement planning which had a Beta of 132 .
\end{abstract}

Keywords: Material Requirement Planning, Procurement Planning, Quality Health Care

\section{Introduction}

Procurement may be defined as the acquisition of goods, works and services according to Baily P. et al., (2008). This embraces not only purchasing, that is, buying of goods, but it also includes hiring of contracts or consultants to carry out services. Standards required in procurement are high quality service, economy and efficiency and fairness in competition. Thus a procedure must be followed and is applicable to all contracts for goods and works.
Public procurement concerns the acquisition of products, works and/or services of significantly improved existing services and products or a new application of organizational innovation for the provision of existing products and services. Innovation can be developed by the individual contractor, or a consortium of suppliers, to further developed partnership with the buyer in the supply chain (Hommen et al., 2009). The World Bank, (1995) refers to Public Procurement as the acquisition of goods, services and works by a procuring entity using public funds. 
Poor procurement planning has been one of the major stumbling blocks to the economic development of Africa and it has been clear that a number of African countries have not paid adequate attention to the proper management of public resources (Basheka, 2004). An efficient public procurement system is vital to the advancement of African countries and is a concrete expression of the national commitment to making the best possible use of public resources (Kabaj, 2003). The influence of new public management (NPM) philosophies in the functioning of the public sector has been embraced procedurally by government departments in a number of African Countries.

In Ghana for instance, there has been an increase in finance by the World Bank for procurement of health sector goods; pharmaceuticals, vaccines, contraceptives and nutritional supplements under various health, population and nutrition projects over the past few years, and this trend is expected to continue. Assistance under these projects supports the procurement of, for example contraceptives for family planning programmes, pharmaceuticals, vaccines and other health sector goods for AIDS, tuberculosis, leprosy, malaria and Maternal and Child Health $(\mathrm{MCH})$ programmes Baily P. et al., (2008).

The bank programmed $\$ 1.8$ billion for the period 1997/98 for the health, nutrition and population sector of which financing for pharmaceuticals accounted for between \$220 million and $\$ 250$ million of this total. Apart from salaries, pharmaceuticals represent the largest category of recurrent health expenditure in most government budgets. The total value of pharmaceuticals changing hands in the developing world is estimated at $\$ 44$ billion (Woodle, 2000). This called for proper procurement planning to provide right inputs at right time, and with right amount. Procurement planning is the process of determining the procurement needs and the timing of their acquisition and funding such that the entire operations are met as required in an efficient way according to BailyP. et al., (2008).

Furthermore, according to Agaba \& Shipman, (2007), procurement planning is the process used by companies or public institutions to plan purchasing activity for a specific period of time. This is commonly completed during the budgeting process. Procurement planning therefore means identifying what needs to be procured, how project needs can best be met, the scope of the goods, works or services required, what procurement strategies or methods to be deployed, setting the time frames, and the responsibilities for the full procurement process. procurement planning is the primary function that sets the stage for subsequent procurement activities. A mistake in procurement planning has wide implications for local governance, measured from the two indicators of accountability and participation. According to James (2004), the ideals of planning suggest that procurement planning can be implemented in an atmosphere of complete harmony. He adds that, as a function, procurement planning endeavors to answer the questions of what do you want to procure; when to procure it; where to procure them from; when the resources be available; the methods of procurement to be use; how timely procurement or failure will affect the user of the item(s); the procuring and disposing entity; efficient in the procurement process; and the people to be involved in the procurement.

Economic commission of Africa (2003) defines procurement planning as the purchasing function through which organization obtain products and services from external suppliers. According to PPDA (2005), Public Procurement Act requires Procuring Entities to plan their procurements. A procurement plan helps Procurement Entities to achieve maximum value for expenditures and enables the entities to identify and address all relevant issues pertaining to a particular procurement before they can publicize their procurement notices to potential suppliers of goods, works and services.

A procurement plan is influenced by a number of factors. These include; the value of the procurement, the type of procurement for example, whether the procurement is sensitive, unique, high risk, or of strategic significance to the procuring entity's success, and the nature of procurement for example, whether it involves intrinsic risks and ethical and process issues. According to Basheka (2008) a good procurement plan brings some sanity in the budgetary allocations and prudent financial management.

However, in Kenya, there is a conspicuous gap in procurement planning particularly in the newly developed County governments. This is following the new County governments budget estimates (The Controller of Budgets (CB), 2013). The government has put in place provisions to ensure realization of her long term objective of improving the quality of life of its citizens. Substantial resources have been committed towards improving service delivery in areas such as infrastructure development and maintenance, rural development, human development and governance, among others. The implementation of these interventions would be incomplete without proper procurement planning (KNBS, 2008).

A procurement plan must be integrated into annual sector expenditure programs to enhance financial predictability (PPOA, 2009) and Public Procurement and Disposal General Manual. Section 26 (3) of the Act and Regulations 20 and 21 make procurement planning mandatory. The procurement plans are prepared as part of the annual budget preparation process as they are necessary to inform the cash flow preparation. The annual procurement planning is an integral part of the budget processes. Therefore it is important to appropriately plan multiyear procurement and to integrate them into the medium term budgetary frameworks problem statement.

Public Procurement Oversight Authority Manual (2009), states that adequate planning and prioritization of needs by each procuring entity is an essential prerequisite to effective procurement for the following reasons: Funding for procurement is unlikely to be sufficient to meet all requirements, and scarce financial resources must be allocated to meet the priority public services before less essential needs 


\subsection{Procurement Planning and Health Care Service Quality}

According to the Pan American Health Organization of the World Health Organization (2006), procurement planning is a dynamic process that requires input from many different categories of professionals. It is therefore recommended that procurement planning be carried out by a multidisciplinary team established specifically for the purpose, with the participation of different technical and administrative professionals who have experience in procurement and supply chain management for the provision of strategic national public health programs. The procurement planning team may draw on expertise from specific advisors when necessary.

According to Johan (2006) further came up with some important service delivery improvement slogans. He said he who fails to plan for service delivery, plans to fail delivering services to the public. And if it cannot be measured, it cannot be improved. If we only plan to comply with regulations, we are not managers, but we are robots. What we plan we must implement. What we implement, we must monitor. We should not be afraid to ask the customer (citizens). They really do know best what they need and what they get. According to Basheka (2004) argues that procurement planning is one of the primary functions of procurement with a potential to contribute to the success of local government operations and improved service delivery. It is a function that sets in motion the entire acquisition/procurement process of acquiring services in local governments.

Mullins (2003) asserts that the contribution of procurement planning in facilitating an efficient and effective service delivery in public sector organizations is generally undisputed in both developed and developing countries. According to the Public Procurement Policy Manual (2009), procurement planning drives different expected results which are different from business as usual such as: reduction in the number of overall contract awards, understanding and managing total cost of ownership, more purchasing options (lease vs. buy), data driven decision making, improved risk mitigation prior to award, more identification of opportunities where suppliers can add value, improved relationships with suppliers which leads to improved service delivery.

According to Mawhood (1983) further adds that effective procurement planning is an important route towards securing the right service to be delivered to the public, and also maximizing the level of service provision, which can be achieved within the local Supporting People. A procurement plan helps Procuring Entities to achieve maximum value for expenditures on services to be delivered and enables the entities to identify and address all relevant issues pertaining to a particular procurement before they publicize their procurement notices to potential suppliers of goods, works and services.

\subsection{Significance of Study}

Public procurement among public hospitals in Kenya has been in the recent past marred with a number of irregularities which is always attested to improper procurement planning. Further, the inadequacy in procurement planning among such entities has led to major challenges witnessed at the various stages of procurement cycle for example during need assessment, materials specification, sourcing for funds among others. The outcome of these inefficiencies in public procurement systems has seen service quality being compromised particularly in Public Hospitals which is a massive Health Care service provider in Kenya. This study sought to assess the role effective public procurement planning practices would play in enhancing service quality in Nakuru Level V Hospital. The findings aimed at drawing conclusions to the Nakuru County Government on the way forward towards enhance health care quality at the Nakuru Level V Hospital. Further, the findings of the study can be used as a point of reference for upcoming researchers since public procurement planning has increasingly received a growing attention among scholars across the country.

\subsection{Objectives of the Study}

i. To establish the effect of material requirement planning on health care service quality in Nakuru Level V Hospital

ii. To determine the influence of resource planning on provision of quality health care services at Nakuru Level V Hospital

iii. To determine the influence of health care capacity planning on provision of quality health care services at Nakuru Level V Hospital

iv. To establish the influence of Master Production Schedule on provision of quality health care services at Nakuru Level V Hospital

\subsection{Research Hypothesis}

$\boldsymbol{H O}_{1}$ : There is no statistically significant effect of materials requirement planning on health care service quality

$\boldsymbol{H O}_{2}$ : There is no statistically significant influence of resource planning on provision of quality health care service.

$\boldsymbol{H O}_{3}$ : There is no statistically significant influence of capacity planning on provision of quality health care services.

$\boldsymbol{H O}_{4}$ : Master production scheduling has no statistically significant influence on heath care service quality.

\subsection{Conceptual Framework}

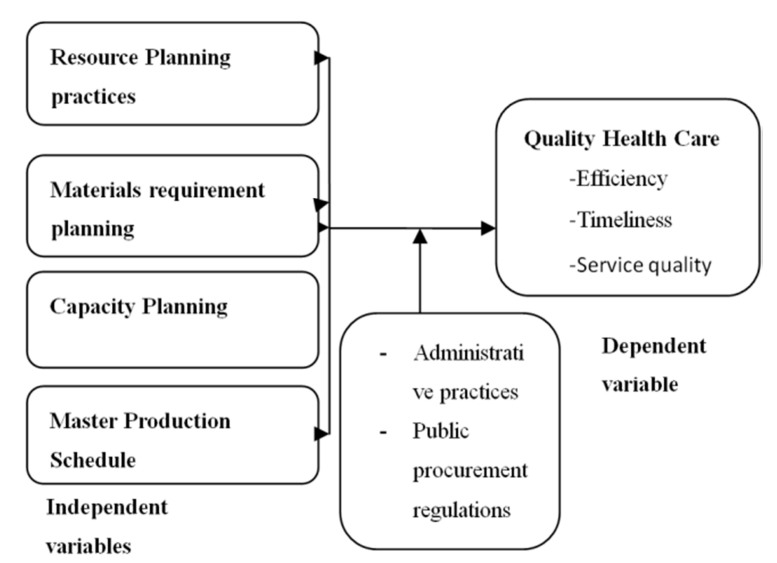

Figure 1. Conceptual Framework. 


\section{Literature Review}

\subsection{Resource Planning Practices}

Collaboration in inter-organizational relationships is often hampered by poor communication (Dyer et al. 2001). According to (Amabire, 2001) organizations must set up procedures such as communication and coordination of processes for collaboration. He further opine that Not all communication mechanisms however are equally effective or efficient. A continuum of media richness has been proposed for various modern modes of communication ranging from person to person mettings for standardized data transfer, such as electronic data interchange (EDI).

Communication is approached on the information systems level. Computer-based information systems are used to process and disseminate information within and between organizations and thus support the accomplishment of the defined processes (Laudon, 2006). Analytical SRM (white rounded squares) aim at storing, analyzing, and applying knowledge about suppliers and personnel dedicated to manage the supplier's relationship. For this, typically performance management and decision support tools (e.g. business intelligence, on-line analytical processing, statistical tools, data warehousing, data mining) are used. The purpose of collaborative SRM (light gray rounded squares) is to improve the quality of supplier collaboration, and, as a result, increase supplier performance and reliability. E-Collaboration tools (e.g. collaborative forecasting and planning), E-Contract management tools, E- Auctions, E-Tendering, and E-RFx tools (e.g. electronic request for information, quotation, and proposal) fall into this category. Operational SRM (dark gray rounded squares), commonly referred to as E-Procurement, includes all necessary tools for ordering and conclusion of a contract such as payment, invoice verification. Typical examples are plan-driven purchasing and desktop purchasing tools, E-Payment, supplier self-service, and supplier portals.

Laudon (2006) further reports that alongside analytical, collaborative, and operational SRM, other tools are needed (dashed rounded squares) to support activities, which are not in the core of procurement. For instance, search engines to retrieve all kind of internal and external information related to sourcing, inventory control systems to build the crucial bridge to the logistics department and requester of goods, business process modeling and enterprise architecture solutions for visualizing, simulating and analyzing different structural aspects of the purchasing department, personnel administration systems for managing workforce related information, finance and controlling systems to define targets and supervise the achievement of objectives, and enterprise content management systems to dispense all kind of documentation.

\subsection{Materials Requirement Planning}

Materials planning address the acquisition, storage, distribution and retrieval of all consumable resources/materials such as suture materials, prostheses, blood, bandages and food among others. Materials planning typically encompass functions like warehouse design, inventory management and purchasing. Material requirement planning is inventory control policy for dependent (known) demand and used in the manufacturing industry where complex products have to be assembled from hundreds or thousands of different parts or components with different manufacturing or supplies lead times. MRP uses integrated computer systems for planning and controlling manufacturing resources, processes and schedule (Emmet \& Granville, 2007).

According to Emmet and Granville, (2007) MRP is a set of logically related procedure, decision rules and records designed to translate a master production schedule into time phased net requirements, and the planned coverage of such requirements for each component. MRP essentially takes a total production schedule and converts it into the necessary raw materials or parts requirements and synchronizes ordering timelines to ensure that materials are on hand when needed. Demand information which is based on firm orders, forecasts or marketing plans is used for developing the master production schedule. This uses Bill of materials for every finished product to calculate components, assemblies and sub assemblies and their quantities for manufacturing in order to ensure availability of all components for manufacturing on time.

The MRP processor uses lead times for each component to determine the latest order date which is required to ensure that all items, materials and components are available at the dates and times required according to the MPS (Emmet \& Granville, 2007). However, the use of MRP in humanitarian assistance is very limited and can only be considered for assembling kits, particularly when different items and components are not on hand and their lead times differ.

\subsection{Capacity Planning Practices}

A sound procurement system has to have a competent professional workforce equipped with defined skills and knowledge for specified procurement jobs (OECD-DAC, 2006). Creating a procurement workforce with the right skills and capabilities can be a challenge, given changes to procurement processes, the introduction or expansion of alternative contracting approaches, and increased reliance on services provided by the private sector (Government Accountability Office, 2005). The procurement workforce "permeates virtually every effort within an agency, including successfully acquiring goods and services and executing and monitoring contracts" (Government Accountability Office, 2005).

Procurement must take a thoroughly professional view of its role in business as a whole and that must include planning (Bailey, et al., 1998). Raymond (2008) also linked lack of a high degree of quality of personnel in public procurement to corruption, which ultimately impedes compliance. Effective training enhances knowledge, skill and behaviors of the people and their performance. Improved performance will lead to increased productivity, increased profits for the 
organization and therefore good results of investing in training (Mullins, 2002). Financial management, in service organizations has been a constraint and an obstacle to other functions that contribute to service delivery (Adams \& Colebourne, 1999).

There is a need to distinguish "good costs" that improves organizational capabilities and quality service delivery from "bad costs" that increase bureaucracy hence becoming obstacles to service delivery (Sun \& Shibo, 2005). Financial accountability using monitoring, auditing and accounting mechanisms defined by the country legal and institutional framework is a prerequisite to ensure that allocated funds are used for the intended purposes (Oliveira-Cruz, et al., 2001). In many developing countries, governments do not have the financial and technical capacity to effectively exercise such oversight and control functions, track and report on allocation, disbursement and use of financial resources (Smee, 2002).

Political and bureaucratic leakage, fraud, abuse and corrupt practices are likely to occur at every stage of the process as a result of poorly managed expenditure systems, lack of effective auditing and supervision, organizational deficiencies and lax fiscal controls over the flow of public funds (Peters, et al., 2000). Parasuraman et al (1996) points that skills deficit within local governments remains a major challenge. A significant number of local governments do not have the managerial, administrative, financial and institutional capacity to meet the rising needs of local people. This situation is exacerbated by the decline of municipal professional and poor linkages between local government and tertiary education sector. As a result these local governments cannot meet their required performance standards hence impacting adversely on the delivery of services.

Providing health facilities with drugs and medical supplies is a complex process involving both the private and public sectors. Governments and health Ministries often lack the management skills required to write technical specifications, supervise competitive bidding, and monitor and evaluate the contract performance. Financial malpractices also could occur at any stage of the process and influence decisions on the model of procurement (direct rather than competitive), on the type and volume of procured supplies, and on specifications and selection criteria ultimately compromising access to essential quality medicines (Miles \& Breen, 2005).

\subsection{Master Production Schedule}

Most studies related to production planning and demand fulfillment used methods such as system simulation, mathematical programming, and algorithms. (Sahin \& Robinson 2002) investigated the relationship between manufacturers and suppliers in a make to order environment, using a system simulation construction model to conduct experimental analysis of the entire factory. They observed three main production design factors: planning horizon length, frozen interval length, and replanning frequency, and observed four environmental factors: ordering cycle length, supplier flexibility, demand limitations, and demand lumpiness.
These factors affect the master production scheduling, advance order commitment, and influence design strategies. For example Volling \& Spengler, (2007) used a system simulation to determine the factors influencing the design costs under the time interval policy of various master production scheduling strategies in a supply chain, including non-frozen interval policy, planning horizon length, frozen interval length, and replanning frequency. Besides, order cycle length, supplier flexibility, demand limitations, and demand lumpiness are four environmental factors affecting master production scheduling costs and instability. They stated that master production scheduling aims at achieving outcomes such as maximizing capacity utilization, customer service quality, and minimizing the inventory level.

\subsection{Quality Health Care}

Quality has become an increasingly predominant part of our lives. People are constantly looking for quality products and services. The existence of this desire for quality has caused firms and organizations throughout the world to consider it as an essential component of any service and production process. Quality is a strategic differentiator tool for sustaining competitive advantage. Improving quality through improving structures and processes leads to a reduction of waste, rework, and delays, lower costs, higher market share, and a positive company image (Logrosen, 2005). Healthcare service is an intangible product and cannot physically be touched, felt, viewed, counted, or measured like manufactured goods. Producing tangible goods allows quantitative measures of quality, since they can be sampled and tested for quality throughout the production process and in later use. However, healthcare service quality depends on service process and customer and service provider interactions.

\subsection{Resource Based View Theory}

Resource-based View theory originated from the work of Wernerfelt, (1984), in which he argued that a firm's strategic resources differences are laxly related to differences in product or service attributes, and thus, to competitive advantages and differences in performance. This view was reinforced by Shrivastava, (1994). Firm resources can be tangible or intangible, and may be developed inside the firm or acquired in the market (Hall, 1992). Resource commitment includes the allocation of tangible and intangible entities available to the companies that enable it to produce efficiently and/or effectively a market offering that has value for some market segment (Hunt, 2000).

The RBV theory of the firm argues that a firm can be regarded as a bundle of resources, and resources that are valuable, rare, imperfectly imitable and substitutable are a firm's main source of competitive advantage (Amit \& Schoemaker, 1993; Barney, 1991; Peteraf, 1993; Wernerfeldt, 1984). According to Barney (1991), the concept of resources includes all assets, capabilities, organizational processes, firm attributes, information, knowledge, etc. controlled by a firm that enable it to conceive and implement strategies that 
improve its efficiency and effectiveness. If these conditions hold, the bundle of resources can sustain the firm's above average returns. Resources are the inputs or the factors available to a company which helps to perform its operations or carry out its activities (Ordaz et al. 2003). The same authors opine that resources, if considered as isolated factors do not result in productivity; hence, coordination of resources is important. Productive activity requires the cooperation and coordination of teams of resources. A capability is the capacity for a team of resources to perform some task or activity. (Grant, 2010)

Hence, the presence of capability enables resources to begin to be utilized, and the potential for the creation of output arises While resources are the source of a firm's capabilities, capabilities are the main source of its competitive advantage (Schmidt \& Keil 2013). Although the resource-based view has emerged as one of the substantial theories of strategic management, it is said that it has overlooked the role of entrepreneurial strategies and entrepreneurial abilities as one of the crucial sources of the competitive advantage of a firm (Akio, 2005). Therefore it is open to criticism that the RBV contains a theory of sustainability but not a theory of competitive advantage (Priem \& Butler, 2001).

Secondly, the concept of a 'rare' resource does not necessarily ensure the competitive advantage of the firm, even if that resource generates a large 'rent' due to its relative scarcity. Likewise Schmidt \& Keil (2013) have also discredited the RBV for assuming that the resources are available to one firm only and that the customers have an infinity demand for them while in reality, efforts to reduce costs have a decreasing marginal effect. This theory is found relevant to this study since the standard of service delivery for any entity and in this case public entity would be largely determined by the resource capacity of the institution.

\section{Research Methodology}

\subsection{Research Design}

The study adopted a descriptive survey research design. The process of a survey design entails collecting information by interviewing or administering a questionnaire to a sample of individuals (Orodho, 2003). This study targeted managers at top, middle and lower levels at Nakuru Level V Hospital hence a survey research design was suitable.

\subsection{Target Population}

Population refers to the entire group of people or things of interest that the researcher wishes to investigate (Sekaran, 2010). Target population is the members of a real or hypothetical set of people, events or objects the researcher wishes to generalize the results of the research (Mugenda \& Mugenda, 2003). The target population for this study were top level managers, middle level mangers as well as lower level managers at Nakuru Level V Hospital. The total number of managers under the three categories currently stands at 98 (HR Records, Rift Valley Provincial General Hospital)
Table 1. Distribution of Respondents.

\begin{tabular}{lllll}
\hline Level & Procurement & Administration & Finance & $\begin{array}{l}\text { Target } \\
\text { Population }\end{array}$ \\
\hline Top level & 2 & 8 & 3 & 13 \\
Middle & 8 & 9 & 7 & 24 \\
Bottom & 13 & 32 & 16 & 61 \\
TOTAL & 23 & 49 & 26 & 98 \\
\hline
\end{tabular}

Source: Human Resource (RVPGH, 2016)

\subsection{Sample Size and Sampling Technique}

The sample size was determined using widely researched and applied formula. Since the target population $N$ is known, the study has adopted the formula of Israel, (1992) as shown in the equation 1 , to determine the sample size, $n$, of case study respondents:

$$
\mathrm{n}=\frac{\mathrm{N}}{1+\mathrm{N}(\mathrm{e})^{2}}
$$

where $\mathrm{n}$ is the optimum sample size, $N$ the target population (i.e. the total number of employees within the respective levels and departments) at Rift Valley Provincial General Hospital, $e$ the probability of error (i.e. the desired precision e.g. 0.05 for $95 \%$ confidence level.) $\mathrm{n}$ is approximately 79 as derived in the equation 2 below:

$$
\mathrm{n}=\left[\frac{98}{1+98(0.05)^{2}}\right]=\frac{98}{1.245}=79
$$

The distribution of sample size according to population characteristics was as follows;

Table 2. Sampling Distribution.

\begin{tabular}{llll}
\hline Level & Target Population & Percentage \% & Sample Size \\
\hline Top level & 13 & 13 & 10 \\
Middle & 24 & 24 & 19 \\
Bottom & 61 & 63 & 50 \\
TOTAL & 98 & 100 & 79 \\
\hline
\end{tabular}

\subsection{Data Collection Instrument}

The study used questionnaire as the instruments for data collection. Questionnaire were used to obtain primary data. This is because questionnaires are fast, cheap and can be self administered, according to (Mugenda \& Mugenda, 2003). The instrument was used since it is considered reliable and capable of obtaining detailed information on the topic of study. Kothari (2004) terms the questionnaire as the most appropriate instrument due to its ability to collect a large amount of information in a reasonably quick span of time. A 5 point Linkert scale where 1 represents the least important response and 5 represents the most important response was employed. In order to minimize on errors, delays and bias, there were a few open ended questions allowing respondents to express personal opinion.

Permission was sought from the respondents to conduct the study through the use of the introductory letter from JKUAT. 


\subsection{Data Processing and Presentation}

Data analysis is the process of bringing orderly structure and meaning to the mass of information collected. It involves examining what has been collected and making deductions and inferences (Kombo \& Tromp, 2006). Data was analyzed using both qualitative and quantitative techniques. Qualitative data was analyzed by giving explanation of information obtained from the empirical literature. Quantitative data was analyzed using descriptive statistics with the help of Statistical Package for Social Sciences (SPSS). This was done through editing and coding variables into common themes to facilitate generation of statistics (Obure, 2002). Statistics in terms of mean Standard deviation, frequency and percentages were generated to reveal the distribution trend in the variables under study. In order to test the relationship between the various independent variables and the dependent variable, inferential statistics were applied. In this case, Karl Pearson correlation coefficient was used to establish whether there is significant relationship between the variables under study. Regression analysis was conducted to test the influence of all the independent variables on the dependent variable. Chi-Square was used to test the Hypotheses. The output was then presented in tables and interpretations were done based on study objectives and research questions. The following regression model was used;

$$
\mathrm{Y}=\mathrm{a}+\beta_{1} \mathrm{X}_{1+} \beta_{2} \mathrm{X}_{2+} \beta_{3} \mathrm{X}_{3+} \beta_{4} \mathrm{X}_{4+} \mathrm{e}
$$

Where:

$$
\begin{gathered}
\mathrm{Y}=\text { Quality Health Care } \\
\mathrm{a}=\text { Constant } \\
\beta=\text { Beta }
\end{gathered}
$$

$$
\begin{gathered}
\mathrm{X}_{1}=\text { Resource Planning } \\
\mathrm{X}_{2}=\text { Materials Requirement Planning } \\
\mathrm{X}_{3}=\text { Capacity Planning } \\
\mathrm{X}_{4}=\text { Master Production Schedule } \\
\mathrm{e}=\text { Error term }
\end{gathered}
$$

\section{Discussion}

\subsection{Reliability Test Results}

In order to produce useful results, the researcher ensured that the questionnaire is reliable and valid through pilot testing. The pilot study involved collecting data from ( 5 respondents) that were randomly selected from the target population who were excluded from the main study. The pilot study was done at Nakuru Level V Hospital 1 on $30^{\text {th }}$ of June, 2016. The findings were as follows;

\begin{tabular}{|c|c|c|c|c|c|}
\hline Variable & $\mathbf{N}$ & Minimum & Maximum & Mean & Std. Deviation \\
\hline Resource availability determines the quality of health care & 67 & 2 & 5 & 4.43 & .633 \\
\hline Available resources at RVPH is adequate & 67 & 1 & 5 & 2.10 & 1.061 \\
\hline Resource planning is based on prevailing market prices & 67 & 1 & 5 & 3.78 & 1.056 \\
\hline Resource planning should aim at meeting regulatory standards and customer needs & 67 & 1 & 5 & 4.09 & .981 \\
\hline Poor resource planning leads to wastage and poor health care quality & 67 & 1 & 5 & 4.39 & .834 \\
\hline Valid N (list wise) & 67 & & & & \\
\hline
\end{tabular}

Table 3. Pilot Test Results.

\begin{tabular}{lll}
\hline Variable & $\begin{array}{l}\text { Cronbach's } \\
\text { alpha }\end{array}$ & Number of Items \\
\hline Resource Planning Practices & .875 & 6 \\
Materials Requirement Planning & .882 & 6 \\
Capacity Planning Practices & .808 & 6 \\
Master Production Schedule & .706 & 5 \\
Quality Health Care & .814 & 7 \\
Cronbach's alpha (average) & .817 & \\
\hline
\end{tabular}

According to table 3 , the results obtained showed that Cronbach's Alpha was 0.817 hence the questionnaire was deemed adequate for the study. This was due to the fact that the value obtained was greater than the alpha value of 0.7 .

\subsection{Resource Planning Practices and Quality Health Care}

Table 4. Resource Planning Practices and Quality Health Care.

Table 4 represents response on the influence of resource planning practices and provision of quality health care at Nakuru Level V Hospital. It was established that resource availability determines the quality of health care as reported by majority of the respondents who agreed (mean=4.43) on the issues. Further, the response on resource availability was less dispersed (std deviation=.633) indicating consensus among the respondents. In addition, majority of respondents disagreed (mean $=2.10)$ that available resources at the facility were not adequate however their opinions were largely varied as indicated by a $\delta=1.061$. Consequently, majority of the respondents agreed (mean $=4.21$ ) that resource plans should be integrated in the annual budgets and respondents seemed to have converging opinions on the variable as indicated by a standard deviation of .616. Table 4 also revealed that at the Nakuru Level V Hospital, resource planning is usually based on the prevailing market prices as majority of the respondents agree (mean=3.78) on the matter despite their opinions being 
varied and widely spread $(\delta=1.056)$ from one another. The respondents also agreed (mean=4.09) that resource planning should aim at meeting regulatory standards and customers needs with focus on providing quality health care. In this case, the opinions of respondents seemed to converge around the mean as evidenced by a $\delta$ of .984 . Finally, it was widely accepted by the respondents that poor resource planning leads to wastage and poor quality health care as indicated by a mean of 4.39 and a standard deviation of .834 showing a general consensus on the issue among the respondents.

\subsection{Material Requirement Planning and Quality Health Care}

Table 5. Material Requirement Planning and Quality Health Care.

\begin{tabular}{|c|c|c|c|c|c|}
\hline Variable & $\mathbf{N}$ & Minimum & Maximum & Mean & Std. Deviation \\
\hline $\begin{array}{l}\text { Material planning address the acquisition, storage, distribution and retrieval of all } \\
\text { consumable resources }\end{array}$ & 67 & 3 & 5 & 4.46 & .559 \\
\hline Blood, bandages, food, prostheses and suture materials are planned for & 67 & 3 & 44 & 4.97 & 1.880 \\
\hline MRP aims at assembling hundreds of different components with different supply lead times & 67 & 2 & 5 & 3.96 & .747 \\
\hline MRP synchronizes ordering timelines & 67 & 1 & 5 & 4.09 & .933 \\
\hline Demand information is key for MRP & 67 & 1 & 5 & 3.72 & .982 \\
\hline MRP is considered in assembling kinds of items where their lead times differ. & 67 & 1 & 5 & 3.79 & 1.095 \\
\hline Valid N (list wise) & 67 & & & & \\
\hline
\end{tabular}

According to table 5, respondents agreed (mean=4.46) that among the issues addressed by material planning in a hospital set up include acquisition, storage, distribution and retrieval of all consumable resource which witnessed a high level of consensus by the respondents $(\delta=.559)$. However much the opinions of the respondents were greatly varied $(\delta=1.880)$, majority strongly agreed (mean=4.97) that blood, bandages, food, prostheses and suture materials are the once majorly planned for in a hospital set up. Further, it was agreed (mean=3.96) that MRP aims at assembling different components with different supply lead times since time is a key determinate of quality health care where the respondents opinions were revolving around the mean as evidenced by a standard deviation of .747. Respondents also agreed as indicate by a mean of 4.09 that MRP synchronizes ordering timelines especially where a number of items are to be utilized together in a particular process of service delivery thereby enhancing the provision of quality health care.

When the respondents were asked to comment on demand information as key factor in MRP, their opinions were less dispersed $(\delta=.982)$ where majority agreed (mean $=3.72)$ on the significance of demand information in implementing MRP. Finally, in attempts to improve the quality of health care, majority of the respondents agree $($ mean $=3.79)$ on the role of MRP in assembling different kinds of items especially where their lead times differ as may be attributed to varied suppliers of the items.

\subsection{Capacity Planning Practices and Quality Health Care}

Table 6. Capacity Planning Practices and Quality Health Care.

\begin{tabular}{|c|c|c|c|c|c|}
\hline & $\mathbf{N}$ & Minimum & Maximum & Mean & Std. Deviation \\
\hline Competent professional workforce is necessary for a sound procurement system & 67 & 2 & 5 & 4.6 & .573 \\
\hline Competent workforce enhances successful acquisition, execution and monitoring of contracts & 67 & 3 & 5 & 4.4 & .585 \\
\hline Procurement plans being responsive and accountable & 67 & 1 & 5 & 2.7 & .997 \\
\hline Procurement personnel are regularly trained & 67 & 1 & 5 & 2.4 & 1.160 \\
\hline Adequate funds is key for improved health care & 67 & 1 & 5 & 4.3 & .863 \\
\hline Valid N (list wise) & 67 & & & & \\
\hline
\end{tabular}

According to table 6, it was established that competent workforce is key to a sound procurement system. This was evidenced by the fact that majority of the respondents strongly agreed (mean=4.63) on the matter besides their opinions converging around the mean to indicate consent among the respondents as indicated by $\delta$ of .573 . In addition, majority of the respondents agreed (mean=4.45) that competent workforce enhances successful acquisition, execution and monitoring of contracts which greatly influences the standard of quality health care. On whether procurement plans were responsive and accountable, majority of the respondents disagreed (mean=2.72) which again was seen to influence the provision of quality health care negatively. Further, a standard deviation of .997 indicated moderate dispersion in the opinions of the various respondents. A sound procurement system requires competency among the procurement personnel which can be promoted through training. However, majority of the respondents reported that procurement personnel at the hospital are not regularly trained as majority disagreed (mean=2.47) on the matter despite their opinions being largely spread from the mean as indicated by a standard deviation of 1.160 . 
Consequently, respondents were asked to comment on the influence of adequate funds on the quality of health care, majority agreed $($ mean $=4.34)$ on the issue and with a $\delta$ of .863 , they seemed to have a general consensus on the role of adequate funds towards the provision of quality health care. It was further reported that appropriate skills for technical specifications is key especially in the context of a hospital or health care provision set up. This was established due to the fact that majority of the respondents agreed (mean=4.15) on the matter besides their opinions being less dispersed $(\delta=.839)$.

Table 7. Master Production Schedule and Quality Health Care.

\begin{tabular}{|c|c|c|c|c|c|}
\hline Variable & $\mathbf{N}$ & Minimum & Maximum & Mean & Std. Deviation \\
\hline Master Production Schedule requires complex programs to compute & 67 & 1 & 5 & 3.99 & .992 \\
\hline MPS systems are readily available at RVPGH & 67 & 1 & 5 & 3.39 & 1.072 \\
\hline Planning horizon length affects health care service standards & 67 & 2 & 5 & 3.93 & .703 \\
\hline Ordering cycles and supplier flexibility key to quality health care & 67 & 2 & 5 & 4.21 & .708 \\
\hline Demand lumpiness influence procurement planning hence health care service provision & 67 & 1 & 5 & 3.79 & .978 \\
\hline
\end{tabular}

Table 7 indicated that majority of the respondents agreed (mean=3.99) that MPS requires complex programs to compute however the moderate dispersion witnessed in their opinions as shown by a standard deviation of 992 . When asked whether MPS systems are available at the facility, majority could not tell as indicated by a mean of 3.39 besides their responses which were quite varied evidenced by a standard deviation of 1.072. On the other hand, majority of the respondents agreed (mean $=3.93$ ) that planning horizon length affects health care service standards and results $(\delta=.703)$ indicated that there was consensus on the matter. It was also reported that ordering cycles and supplier flexibility is key to quality health care as agreed (mean=4.21) upon by majority of the respondents besides their opinions seeming to converge around the mean as indicated by a standard deviation of .708 .

Further, it was established that demand lumpiness influenced procurement planning thereby negatively affecting the provision of quality health care. This revelation was established as majority of the respondents agreed on the matter besides their opinions being closely consenting to each other as shown by a standard deviation of .978 .

\subsection{Public Procurement Planning and Quality Health Care Services}

The study sought to indicate the extent to which they agreed to the relationship between procurement planning practices and provision of quality health care. The respondents were asked to agree on the various factors describing the success of procurement planning in enhancing the provision of quality health care. The findings were as follows;

Table 8. Public Procurement Planning and Quality Health Care Service.

\begin{tabular}{|c|c|c|c|c|c|}
\hline Variable & $\mathbf{N}$ & Minimum & Maximum & Mean & $\begin{array}{l}\text { Std. } \\
\text { Deviation }\end{array}$ \\
\hline Quality is a differentiating tool for sustaining competitive advantage & 67 & 3 & 5 & 4.45 & .634 \\
\hline Improved quality leads to reduction of waste, rework and delay of health care service provision & 67 & 1 & 5 & 4.3 & .839 \\
\hline Health care services at RVPGH are of quality & 67 & 1 & 5 & 3.2 & 1.152 \\
\hline Quality health care is defined by timelines and consistency & 67 & 2 & 5 & 4.0 & .787 \\
\hline Quality health care means affordability, confidentiality, responsiveness and facilities & 67 & 2 & 5 & 4.3 & .746 \\
\hline Quality health care is influenced by experience, individual abilities and personalities & 67 & 2 & 5 & 4.3 & .717 \\
\hline Procurement planning enhances the provision of quality health care. & 67 & 2 & 5 & 4.4 & .700 \\
\hline Valid N (list wise) & 67 & & & & \\
\hline
\end{tabular}

Table 8 ascertained that quality is a differentiating tool for sustaining competitive advantage as most respondents agreed $($ mean $=4.45)$ and with a standard deviation of .634 , it was established that their opinions were more or else similar. They further agreed (mean=4.31) that improved quality leads to a reduction of waste, rework and delay of health care service. The respondents' opinion on the matter was less dispersed from each other as indicated by a standard deviation of .839 . Consequently, majority of the respondents could not comment strongly on whether health care services at Nakuru Level V Hospital are of quality hence remained neutral (mean=3.28) on the matter. The results $(\delta=1.152)$ on the matter further showed a large disparity in the opinions of the respondents as compared to the mean.

The study also established that quality health was defined by timeliness and consistency by majority of the respondents as indicated by a mean of 4.04 and a standard deviation of .787 revealing consent by most respondents. Respondents further agreed $($ mean $=4.33)$ and possessed closely related opinions $(\delta=.746)$ that quality health also means affordability, confidentiality, responsiveness and facilities.

Besides other factors that influence quality health care 
provision, respondents agreed (mean=4.39) that quality health care is also influenced by the experience, individual abilities and personalities with regard to practitioners and this also evidenced a great convergence of opinions as shown by a standard deviation of .717. Finally, the study ascertained the need for procurement planning regarding the provision of quality of health care at the Nakuru Level V Hospital. This was attested to the fact that majority of the respondents agreed (mean $=4.42$ ) that procurement planning enhances the provision of quality health care besides the respondents' opinions showing convergence $(\delta=.700)$ around the mean.

\subsection{Regression Analysis}

Table 9. Regression Table.

\begin{tabular}{lllll}
\hline Model & R & R Square & Adjusted R Square & Std. Error of the Estimate \\
\hline 1 & $.726^{\mathrm{a}}$ & .5270 & .498 & 2.54055 \\
\hline
\end{tabular}

a. Predictors: (Constant), Resource Planning practices, material requirement planning practices, Capacity planning practices, Master Production Schedule

The results in Table 9 showed that the value obtained for $\mathrm{R}$, which is the model correlation coefficient was $\mathrm{R}=0.726$ which was higher than any zero order value in the table. This indicated that the model improved when more variables were incorporated when trying to analyze influence of public procurement planning practices on provision of quality health care. The adjusted $r$-square value of, $r=0.498$, also indicated that the multiple linear regression model could explain for approximately $49 \%$ of the variations in the public procurement planning practices.

Table 10. Table of Co-efficient

\begin{tabular}{|c|c|c|c|c|c|}
\hline \multirow{2}{*}{ Model } & \multicolumn{2}{|c|}{ Unstandardized Coefficients } & \multirow{2}{*}{$\begin{array}{l}\text { Standardized Coefficients } \\
\text { Beta }\end{array}$} & \multirow{2}{*}{ t } & \multirow{2}{*}{ Sig. } \\
\hline & B & Std. Error & & & \\
\hline (Constant) & 13.255 & 4.422 & & 2.998 & .004 \\
\hline RP & .132 & .133 & -.132 & -.991 & .045 \\
\hline MRP & .117 & .062 & .212 & 1.904 & .042 \\
\hline $\mathrm{CP}$ & .372 & .148 & .334 & 2.506 & .015 \\
\hline MPS & .359 & .158 & .265 & 2.271 & .027 \\
\hline
\end{tabular}

a. Dependent Variable: Quality Health Care

From the full regression model in table 10, the regression equation was obtained. Using the unstandardized beta coefficients, the following regression equation was developed.

$$
\mathrm{Y}=13.255+0.1 .32 \mathrm{X}_{1}+0.117 \mathrm{X}_{2}+0.372 \mathrm{X}_{3}+0.359 \mathrm{X}_{4}+\mathcal{E}
$$

From the full regression model, the beta values were obtained which explained the regression equation. The standardized beta coefficients give a measure of the influence of each variable to the model. Regarding the inference of the influence of public procurement planning and quality health care, the study revealed that capacity planning had the greatest influence on quality health care $($ Beta $=.372)$, followed by master production schedule (Beta $=.359)$, then resource planning $(\mathrm{Beta}=.117)$ and finally material requirement planning which had a Beta of .132

\subsection{Hypothesis Testing}

Hypothesis testing was done using Chi Square at 0.05 level of significance. The calculated Chi Square values were 37.194, 33.119, 39.134, and 42.179 for Resource planning, MRP, Capacity Planning and MPS.

To reject or accept the null hypothesis, Chi Square was used to analyze the findings and the results were as follows;

Table 11. Chi Square Results.

\begin{tabular}{lllll}
\hline Test Statistics & Resource Planning & Material requirement Planning & Capacity Planning & Master production schedule \\
\hline Chi-Square & $37.194^{\mathrm{a}}$ & $33.119^{\mathrm{b}}$ & $39.134^{\mathrm{a}}$ & $42.179^{\mathrm{c}}$ \\
Df & 12 & 11 & 12 & 10 \\
Asymp. Sig. & .000 & .001 & .000 & .000 \\
\hline
\end{tabular}

Table 11 showed that all the p-values $\left(X^{2}(12)=37.194\right.$, $p=.000, X^{2}(11)=33.119, p=.001, X^{2}(12)=39.134, p=.000$, and $\left.X^{2}(10)=42.179, p=.000\right)$. All the table values are less than .05 level of significance which led to the rejection of null hypotheses hence conclusions that There is statistically significant effect of materials requirement planning on health care service quality; There is statistically significant influence of resource planning on provision of quality health care service; There is statistically significant influence of capacity planning on provision of quality health care services and that Master production scheduling has statistically significant influence on quality health care. 
Table 12. ANOVA Table

\begin{tabular}{llllll}
\hline Model & Sum of Squares & Df & Mean Square & F & Sig. \\
\hline Regression & 137.469 & 4 & 34.367 & 5.325 & $.001^{\mathrm{b}}$ \\
Residual & 400.172 & 62 & 6.454 & & \\
Total & 537.642 & 66 & & & \\
\hline
\end{tabular}

a. Dependent Variable: Quality health care

b. Predictors: (Constant), Resource Planning, Material Requirement Planning, Capacity planning, Master production schedule

From table 12 above, the level of significance was 0.001 with an $F$ value of 5.325. This indicated that there is a statistically significant relationship between public procurement planning practices and provision of quality health care because $\mathrm{P}$ value is less than 0.05 .

\subsection{Conclusions}

There is a positive relationship $(\mathrm{r}=.033)$ between resource planning practices and provision of quality health care though the relationship is weak compared to other public procurement planning practices. It was also concluded that resource availability determines the quality of health care and that available resources at the Nakuru Level V Hospital were not adequate. The study also concluded that resource plans should be integrated in the annual budgets and that at the Rift Valley Provincial Hospital, resource planning is usually based on the prevailing market prices. Consequently it was concluded that resource planning should aim at meeting regulatory standards and customers needs with focus on providing quality health care otherwise poor resource planning leads to wastage and poor quality health care.

The findings of the study led to the conclusion that there is a positive moderate relationship $(\mathrm{r}=.237)$ between material requirement planning and provision of quality health care. It was further concluded that the scope of material planning in a hospital set up include acquisition, storage, distribution and retrieval of all consumable. Consequently, among the materials that were planned for included blood, bandages, food, prostheses and suture materials. Further, it was concluded that MRP aims at assembling different components with different supply lead times since time is a key determinate of quality health. In addition, MRP synchronizes ordering timelines especially where a number of items are to be utilized together in a particular process of service delivery thereby enhancing the provision of quality health care.

The research concluded that there is significant positive relationship $(\mathrm{r}=.353)$ between capacity planning practices and provision of quality health care as manifested at the Rift Valley Provincial General Hospital. In this regard, it was concluded that competent work force is key to sound procurement system since it enhances successful acquisition, execution and monitoring of contracts which greatly influences the standard of quality health care. However, it was concluded that procurement plans at Nakuru Level V Hospital were not responsive and accountable thereby influencing the provision of quality health care negatively. Adequacy of funds directly impacted on the quality of health care besides availability of appropriate skills regarding technical specifications.

The study concluded that there is a significant positive relationship $(\mathrm{r}=.347)$ between master production schedule systems and the provision of quality health care. On the other hand, it was concluded that MPS requires complex programs to compute. It was further concluded that planning horizon length affects health care service standards. It was also concluded that ordering cycles and supplier flexibility is key to quality health care. Further, it was deduced that demand lumpiness influenced procurement planning thereby negatively affecting the provision of quality health care.

The results $(p=0.001)$ with an $F$ value of 5.325 indicated that there is a statistically significant relationship between public procurement planning practices and provision of quality health care because $\mathrm{P}$ value is less than 0.05 . Regarding the influence of public procurement planning and quality health care, the study concluded that capacity planning had the greatest influence on quality health care $($ Beta $=.372)$, followed by master production schedule (Beta $=.359)$, then resource planning $(\mathrm{Beta}=117)$ and finally material requirement planning which had a Beta of .132. As such, it was concluded that quality is a differentiating tool for sustaining competitive advantage. This was established to so since improved quality leads to a reduction of waste, rework and delay of health care service. It was further conclude that quality health care was defined by timeliness and that quality health care also means affordability, confidentiality, responsiveness and facilities. Besides other factors that influence quality health care provision, it was also concluded that quality health care is also influenced by the experience, individual abilities and personalities with regard. This was attested to the fact that procurement planning enhances the provision of quality health care.

\subsection{Recommendations}

Since resource availability determines the quality of health care, the study recommends that resource plans should be integrated in the annual budgets in order to ensure adequate allocation of funds in attempt to improve health care quality at the Nakuru Level V Hospital.

The study also recommends application of MRP systems to synchronize ordering timelines especially where a number of items are to be utilized together in a particular process of service delivery to enhance the provision of quality health care.

The study revealed that competent workforce is key to a sound procurement system which calls for professionally qualified individuals to undertake procurement functions at 
Nakuru Level V Hospital. This will improve procurement performance and consequently improved health care quality at the facility.

The study also recommends that besides other efforts to improve health care quality, availability of appropriate skills regarding technical specifications and competent health care personal are essential in promoting quality health care standards.

\section{References}

[1] Agaba, E. \& Shipman, N. (2007). "Public Procurement Reform in Developing Countries: The Kenyan Experience." Boca Raton, FL: Academics Press.

[2] Agaba, E. \& Shipman, N. (2006). Public Procurement Reform in Developing Countries: The Ugandan Experience.

[3] Amit, R., \& Schoemaker, P. (1993). 'Strategic assets and organizational rent'. Strategic Management Journal, (1), pp. 3346.

[4] Bailey, P., Farmer, D., Jessop, D., \& Jones, D. (2004). Purchasing Principles and Management, $\left(8^{\text {th }}\right.$ Ed.), Prentice Hall: Great Britain

[5] Cooper, C., \& Schindler, P. (2008). Business research methods (10 ${ }^{\text {th }}$ Ed.). Boston: McGraw-Hill.

[6] Cox, J., \& Hassard, J. (2005). Triangulation in organizational research: A representation. Organization Science, 12, 109-133.

[7] Development Assistance Committee, (2005). Harmonizing Donor Practices for Effective Aid Delivery, Vol. 3. Strengthening Procurement Capacities in Developing Countries. Paris, France: OECD.

[8] Economic Commission of Africa (2003). Public Sector Management Reforms in Africa. Addis Ababa, Ethiopia: Author.

[9] Emmett, S., \& Granville D. (2007) Excellence In Inventory Management: How To Minimise Costs And Maximise Service, $\left(1^{\text {st }}\right.$ Ed) Liverpool Academic Press.

[10] Hommen, L. (2009). Public Procurement and Innovation: Towards Taxonomy. Journal of Public Procurement, Vol. 9, Issue 1.

[11] James, U. (2004). Public Policy and the African Environment: An Examination of the Theory and practice of the planning process of the continent. In Kalu, A. K. ( $7^{\text {th }}$ Ed.). Agenda Setting and Public Policy in Africa; Ashagte, England.

[12] Johan, N., (2006). Planning for Service Delivery Improvement. S D R 15(2) 106-109.

[13] John A., Parnell, L., Lester, Zhang Long, Mehmet Ali Köseoglu, (2012) "How environmental uncertainty affects the link between business strategy and performance in SMEs: Evidence from China, Turkey, and the USA", Management Decision, Vol. 50 Iss: 4, pp. 546-568.

[14] Kabaj, O. (2003). The Challenge of African Development. Oxford University Press.

[15] Kombo, D., \& Tromp, D., (2006). Proposal and Thesis Writing; An introduction: Nairobi: Paulines Publications Africa.
[16] Kothari. C. R. (2004), Research Methodology: Methods and Techniques, (2 ${ }^{\text {nd }}$ Ed.), Sri Lanka: New Age International Publisher.

[17] Mahmood, S., (2010). Public procurement and corruption in Bangladesh. Confronting the challenges and opportunities. Journal of public administration and policy research, 2 (6), 103-111.

[18] Mcloughlin, C., \& Batley, R. (2012). 'The Effects of Sector Characteristics on Accountability Relationships in Service Delivery'. Working Paper 350. London: ODI.

[19] Miles, M. B., \& Huberman, A. (1994). Qualitative data analysis: An expanded sourcebook ( $2^{\text {nd }}$ Ed.). Thousand Oaks, CA: Sage.

[20] Mugenda, O. M., \& Mugenda, A. G., (2003). Research methods: Quantitative \& qualitative approaches. Nairobi: African Centre for Technology Studies.

[21] Orodho, C. (2003). Elements of Education and Social Science Research Methods. Kanezja Publishers.

[22] Otieno (2004). Procurement activities in public institutions. Unpublished thesis. Jomo Kenyatta University of Science and Technology, Kenya.

[23] P. Th. Houngbo, G., Wilt, D., Medenou, L., Dakpanon, Bunders \& Ruitenberg, J. (2012). Policy and Management of Medical Devices for the Public Health Care Sector in Benin, Public Health Methodology, Environmental and Systems Issues, Prof. Jay Maddock $\left(8^{\text {th }}\right.$ Ed. $)$ ISBN: 978-953-51-0641-8.

[24] Parasuraman, A. (1996). E-S-QUAL: a multiple-item scale for assessing electronic service quality. Journal of Retailing 64 (1), $12-40$.

[25] Peteraf, M. (1993). 'The cornerstones of competitive advantage: A resource-based view', Strategic Management Journal, 14 (3), pp. 179-191.

[26] Peters, D., Elmendorf, A., Kandola, K., \& Chellaraj, G. (2000). "Benchmarks for Health Expenditures, Services and Outcomes in Africa during the 1990s."Bulletin of the World Health Organization. Vol. 78, (6): pp. 761-69.

[27] Public Procurement Oversight Authority (2007). Assessment of the Procurement System in Kenya. Nairobi: PPOA.

[28] Randolph, W. A., \& Blackburn, R. S. (1989). Managing organization behavior. Homewood, IL.

[29] Raymond, J. (2008). Benchmarking in public Procurement. Benchmarking: An International Journal, 15 (6), 782-793.

[30] Sahin, F., \& Robinson, E. (2002). Flow coordination and information sharing in supply chains: Review, implications, and directions for future research. Decision Science, 33 (4), pp. 505-535.

[31] Sekaran, U., \& Bougie, R. (2010). Research Methods for Business: A Skill-building Approach. (5 ${ }^{\text {th }}$ Ed.). Chichester: John Wiley.

[32] Smee, C. (2002). "Improving Value for Money in the United Kingdom National Health Service: Performance Measurement and Improvement in a Centralized System." Improving Health Systems Performance in OECD Countries. Vol. 23, pp 34-45. 
[33] Srivastava, S. (2007). Green supply chain management: a state-of-the-art literature review, International Journal of Management Reviews, Vol. 9 No. 1, pp. 53-80.

[34] Volling, T., \& Spengler, T. (2008). Configuration of Order-Driven Planning Policies. In Operations Research Proceedings 2007 (pp. 441-446). Springer Berlin Heidelberg.

[35] Weele, A. (2010). Purchasing and Supply Chain Management: Analysis, Strategy, Planning and Practice $\left(5^{\text {th }}\right.$ Ed.). Andover: Cengage Learning.

[36] Wernerfelt, B. (1984). 'A Resource-based view of the firm', Strategic Management Journal, 5 (2), pp. 171-180.

[37] WHO (2007). Development Effectiveness Achieving Development Outcomes: The Millennium Challenge Report 2007.
[38] Wittig, W. (1999). Building Value through Public Procurement: A Focus on Africa. paper presented to the $9^{\text {th }}$ international Anti-Corruption conference.

[39] Woodle, D. (2000). Vaccine procurement and self-sufficiency in developing countries. Health policy and planning, 15 (2), 121-129.

[40] World Bank Report. (2007). World Development Report: Development and the Next Generation, Oxford University Press, New York, NY.

[41] World Bank, (2000). Can Africa Claim the twenty first Century?. The World Bank, Washington D. C. 